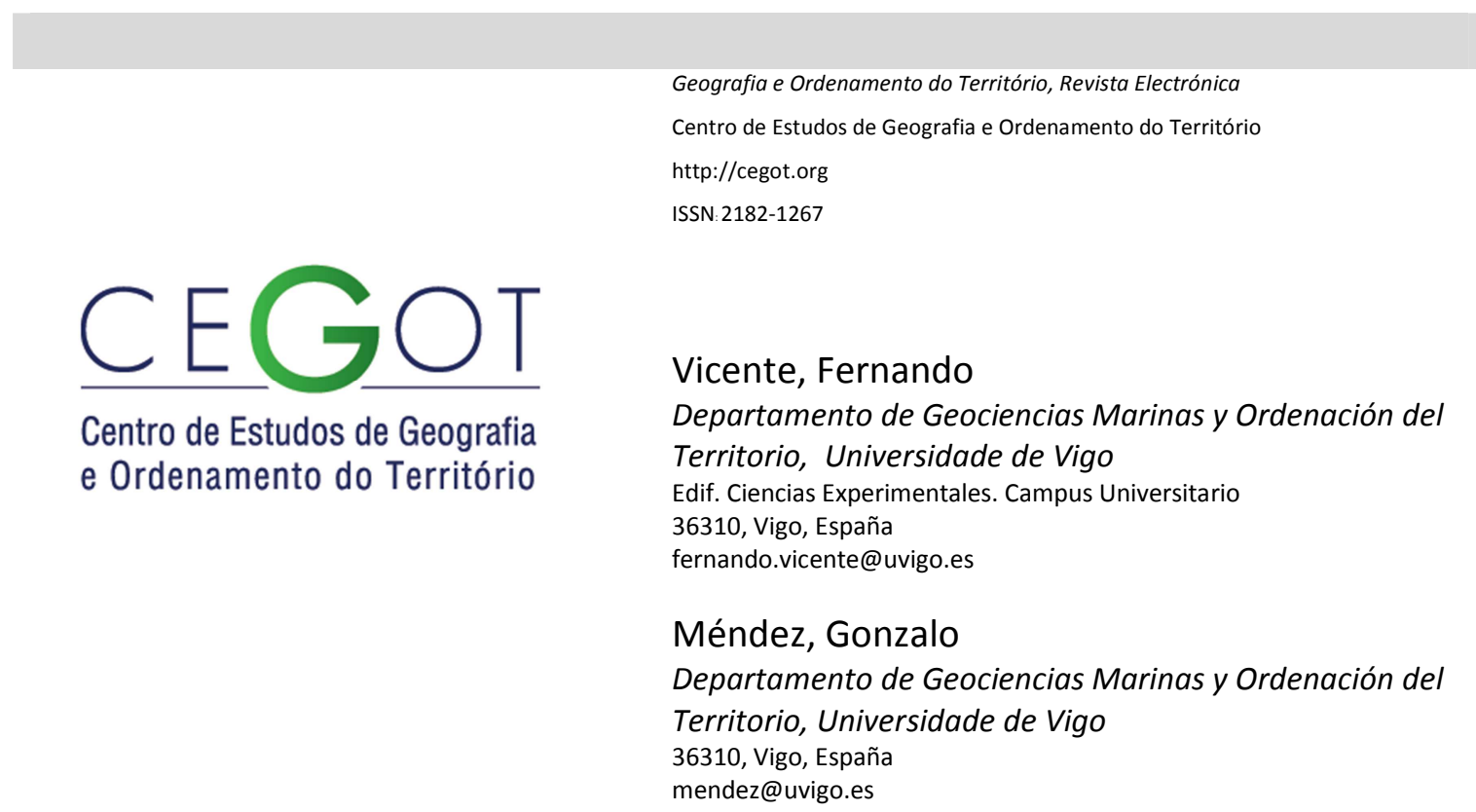

\title{
Análisis de la participación pública transfronteriza en las consultas ambientales entre España y Portugal
}

Referência: Vicente, Fernando; Méndez, Gonzalo (2015). Análisis de la participación pública transfronteriza en las consultas ambientales entre España y Portugal. (GOT), n.o 7 (junho). Centro de Estudos de Geografia e Ordenamento do Território, p. 327-358, dx.doi.org/10.17127/got/2015.7.015

\section{Resumen}

En los últimos tiempos, la Evaluación de Impacto Ambiental Transfronteriza (EIAT) en el contexto ibérico ha experimentado un importante incremento en el número de proyectos transfronterizos, que han sido sometidos a consultas ambientales en el país vecino. Teniendo en cuenta que la cuestión de la participación pública constituye una pieza clave para evaluar la efectividad de los procedimientos de consultas ambientales transfronterizas, el presente trabajo tiene por objeto analizar dicha participación pública en la etapa más reciente. El análisis de la regulación actual de ambos países sobre la participación transfronteriza revela que ésta es bastante limitada respecto a la atribución del derecho a participar, y por otra parte, los casos de estudio muestran que la involucración de la sociedad civil en los trámites de consulta es prácticamente inexistente.

Palabras clave: evaluación de impacto ambiental; consulta transfronteriza; España; Portugal; participación pública. 


\begin{abstract}
In recent times the Transboundary Environmental Impact Assessment (TEIA) in the Iberian context has undergone a significant increase in the number of cross-border projects, submitted to environmental consultations in the neighbour state. Taking into account that the issue of public participation is a key element to assess the effectiveness of the processes of transboundary environmental consultations, this paper aims to analyze such participation in the most recent period. The analysis of the current regulation of both states in transboundary participation reveals that it is fairly restrictive on attributing the right to participate on the one hand, and, on the other, the case studies show that the involvement of the civil society in the consultations stage is practically non-existent.
\end{abstract}

Keywords: environmental impact assessment; transboundary consultation; Spain; Portugal; public participation.

\title{
Resumo
}

Nos últimos tempos, a Avaliação do Impacto Ambiental Transfronteiriça (AIAT) no contexto ibérico tem experimentado um importante incremento no número de projectos transfronteiriços financiados pelos fundos da UE que têm sido submetidos a consultas ambientais no país vizinho. Tendo em conta que a questão da participação pública constitui uma peça finque para avaliar a efectividade dos procedimentos de consultas ambientais trans-fronteiriças, o presente trabalho tem por objeto analisar dita participação pública na etapa mais recente. $\mathrm{A}$ análise da regulação actual de ambos os países sobre a participação transfronteiriça revela que esta é bastante limitada com respeito à atribuição do direito a participar, e por outra parte, os casos de estudo mostram que o envolvimento da sociedade civil nos trâmites de consulta é praticamente inexistente

Palavras-chave: Avaliação do impacto ambiental; consulta transfronteiriça; España; Portugal; participação pública

\section{Introducción}

La participación es un elemento indispensable que debe insertarse al inicio, durante y después del proceso de toma de decisiones en los procedimientos de Evaluación de Impacto Ambiental (EIA), nacionales y transfronterizos, pues permite mejorar la calidad y legitimidad de la opción finalmente seleccionada. Introducir un principio de deliberación pública en el procedimiento de EIA enriquece la información y los datos disponibles, fortalece el contraste de distintas alternativas, aprovecha las experiencias y la capacidad de todos los involucrados, desarrolla nuevas capacidades en la gestión, y fortalece la legitimidad y confianza de la decisión adoptada.

Esta importancia crucial deriva de los beneficios que la participación pública produce: información, transparencia, rendición de cuentas, confianza, cooperación, toma de 
conciencia, apoderamiento y responsabilidad pública (Bruch et al. 2007). En el contexto europeo, la actual "Directiva 2011/92/UE relativa a la evaluación de las repercusiones de determinados proyectos públicos y privados sobre el medio ambiente", conocida como la Directiva EIA, también reconoce estos efectos al considerar que al facilitarse la "participación real del público" en la adopción de esas decisiones mediante la expresión de opiniones e inquietudes que pueden ser pertinentes, y que las autoridades decisorias puedan tener en cuenta, favorecen de esta manera la "responsabilidad y la transparencia del proceso decisorio", y contribuyen a "la toma de conciencia por parte de los ciudadanos" sobre los problemas medioambientales y al respaldo público de las decisiones adoptadas ${ }^{1}$. En este mismo sentido, organizaciones internacionales como la Organización para la Cooperación y el Desarrollo Económico (ODCE, 2001), asumen que los costes de la participación deben incorporarse como costes naturales de eficiencia, porque en realidad no se trata sólo de participar, sino de crear las tramas institucionales para que dicha participación sea posible y verdaderamente eficaz.

El análisis de la participación pública en un marco transfronterizo obliga a contextualizarla dentro del procedimiento ambiental especial en el que halla inserta. Entre las posibles definiciones que las consultas ambientales transfronterizas ostentan, proponemos aquella que la define como: el procedimiento de notificación y respuesta internacional que se desencadena cuando un país, denominado estado de origen, aprecia que la ejecución de un determinado proyecto previsto en su territorio puede entrañar posibles efectos ambientales significativos sobre el medio ambiente de otro país, país afectado. Este procedimiento incorpora, entre sus fases, un trámite de información y consulta de las administraciones y público en el país potencialmente afectado, a fin de que éstos participen en el mismo mediante alegaciones y comentarios. El fundamento para el conocimiento e intervención de los no nacionales se halla basado en los principios de cooperación internacional, de prohibición de causar daño y de no discriminación que se han venido consolidando en el ámbito de la comunidad internacional a través de un paulatino reconocimiento por la jurisprudencia, tratados y declaraciones (Knox, 2002; Craik, 2008). La vulneración del derecho de participar del Estado afectado en los procesos de evaluación ambiental de

\footnotetext{
${ }^{1}$ El considerando 160 de la Directiva establece: "La participación real del público en la adopción de esas decisiones le permite expresar opiniones e inquietudes que pueden ser pertinentes y que las autoridades decisorias pueden tener en cuenta, favoreciendo de esta manera la responsabilidad y la transparencia del proceso decisorio, y contribuyendo a la toma de conciencia por parte de los ciudadanos sobre los problemas medioambientales y al respaldo público de las decisiones adoptadas". Directiva 2011/92/UE del Parlamento Europeo y del Consejo, de 13 de diciembre de 2011.
} 
proyectos e infraestructuras que pueden producir efectos significativos en país vecino constituye el punto crítico del procedimiento transfronterizo.

La participación pública en la EIAT se consigue estableciendo trámites abiertos a la consulta en el procedimiento; informando y notificando al público interesado del país afectado; proporcionando información de forma clara y precisa sobre los efectos transfronterizos, el proyecto y sobre el proceso de toma de decisión; así como estableciendo lugares de consulta y de accesibilidad a este público no nacional. Pero más allá del cumplimiento de las exigencias procedimentales respecto al trámite formal de información y legitimación para participar, la toma en consideración de las alegaciones y comentarios transfronterizos y su influencia en la toma de decision por el Estado de origen, constituyen la cuestión de fondo que fundamenta la razón de ser de las consultas transfronterizas en sede ambiental.

El propósito de este artículo es analizar la participación pública en los procedimientos de consultas transfronterizas entre España y Portugal. Para alcanzar este objetivo se expondrá una breve referencia a la literatura relacionada y a la práctica en los sistemas EIA, abordando esta participación transfronteriza en este contexto ibérico en conexión con las tendencias actuales. A continuación, describiremos el régimen normativo de la participación pública y a los titulares del derecho de participación a la luz de los convenios internacionales suscritos por España y Portugal sobre esta materia y las Directivas aprobadas sobre evaluación de impacto ambiental que han sido transpuestas. Seguidamente, analizaremos cómo ha sido la participación pública transfronteriza en los casos más recientes, para finalmente extraer una serie de conclusiones y propuestas de mejora que contribuyan a fortalecer y armonizar la participación transfronteriza en este contexto.

Para el análisis de la participación hemos recurrido a dos tipos de fuentes: a) los "Informes de consulta transfronteriza", proporcionados por la Subdirección General de Evaluación Ambiental del Ministerio de Medio Ambiente y Medio Rural y Marino de España (MARM) y por la Agência Portuguesa de Ambiente -APA- en el caso de Portugal, de evaluaciones de impacto ambiental que contienen datos clave para identificar los índices de participación; y b) las declaraciones ambientales de cada uno de los proyectos sometidos a EIAT que han sido publicadas en Boletín Oficial del Estado en España y en el Diario de la República en Portugal.

A través de la consulta del programa SABIA (España) del portal web del Ministerio de Agricultura, Alimentación y Medio Ambiente (MAGRAMA) y del programa SIAIA DIGITAL (Portugal) del Ministério do Ambiente, do Ordenamento do Território e do Desenvolvimento 
Regional de Portugal (MAOTDR), se ha accedido a información oficial de los procedimientos nacionales en tramitación. A través de las declaraciones ambientales publicadas en el Boletín Oficial del Estado de España y en el Diário da República de Portugal se han podido completar datos sobre la tramitación transfronteriza de proyectos a fin de verificar cómo han sido tenidos en cuenta los comentarios y alegaciones transfronterizas.

\section{La literatura sobre participación pública}

La literatura académica ha considerado la participación pública un elemento fundamental del procedimiento de EIA (Palerm, 2000; Wood, 2003; Hartley and Wood, 2005; Jay et al. 2007; Fischer et al., 2008). Existe un unánime consenso al respecto, que afirma de forma taxativa que la EIA sin consulta ni participación no es EIA (Wood, 2003; Bruch et al., 2007). Furia and Wallace-Jones (2000) profundizan en este aspecto al concretar que la participación debe medirse en términos de efectividad alcanzable a través del cumplimiento de una serie de objetivos que persigan la involucración del público en los procesos de ElA. Así se ha desarrollado una literatura (Beierle and Cayford, 2002; André et al., 2006, O'Faircheallaigh, 2010, entre otros) que junto con organizaciones internacionales como la Asociación Internacional de Impacto Ambiental (IAIA) y y la Comisión Económica para Europa $(C E P E)^{3}$ a través de documentos y guías internacionales, han venido convergiendo en la necesidad de configurar una serie de objetivos y principios que sirvan de orientación para incorporar al público en los procesos ambientales. Entre estos objetivos destacan, entre otros, la necesidad de que los procesos de participación se adapten a cada contexto, se proporcione información al público de forma proactiva, de forma abierta y transparente, y que ésta sea tratada con rigor y credibilidad.

A pesar de la existencia de estas orientaciones teóricas, la práctica en muchos sistemas de EIA ha puesto en evidencia que éstas no han sido observadas en muchos casos (Petts, 1999, Wood, 2003; Wang et al., 2003; Glasson et al., 2005; Hartley and Wood, 2005). Las causas principales son atribuidas a que las consultas y participación no se llevan a cabo en las fases

\footnotetext{
2"Participation Public International Best Practice Principles" IAIA, 2006.Special Publication Series No. 4. http://www.iaia.org/publicdocuments/special-publications/SP4\%20web.pdf

$3^{3}$ Guidelines on public participation in transboundary EIA" CEPE, 2006. http://www.unece.org/fileadmin/DAM/env/documents/2006/eia/ece.mp.eia.7.pdf
} 
iniciales de los procedimientos, a la naturaleza limitante de los mecanismos de participación empleados, a la pobre contribución de los participantes, así como a los excesivos costes en tiempo y recursos que se necesitan para llevar a cabo un efectivo proceso de participación (Bisset, 2000; Hartley and Wood, 2005; Paliwal, 2006).

En esta literatura ha surgido un foco de interés en evaluar y comparar el éxito de los procesos participativos entre los diversos modelos existentes. Estas investigaciones se han enfrentado al hecho de que los ejercicios de participación son únicos en términos de objetivos y el contexto socio-político en el que tienen lugar y, por lo tanto, difícilmente comparables (Rowe and Frewer, 2004). Por ello, la influencia de la participación pública en las decisiones finales relacionadas con la EIA ha variado mucho entre los países. Así, en sistemas de EIA avanzados como los Países Bajos y Dinamarca, se insiste en la participación pública ya en las fases más iniciales de la EIA, mientras que en otros, como Canadá, la participación pública se garantiza a través de la verificación del proceso por comisiones de expertos independientes (Van de Gronden et al., 1994; Wood, 2003, Glasson et al., 2005). Más recientemente se asiste a un resurgimiento de una literatura que apunta a la necesidad de poner cada vez mayor énfasis en la introducción de procedimientos flexibles y mantener todas las opciones abiertas en el momento de la participación (Fischer, 2008; Martínez, 2008; Gauthier, 2011). Así, el análisis de la participación que exponemos, quiere sumarse a estas líneas de interés por la participación real y efectiva, teniendo en cuenta la escasa atención sobre esta cuestión prestada por los estudios ibéricos realizados hasta la fecha.

\section{La regulación de la participación transfronteriza}

Analizar esta pieza esencial del procedimiento de la EIAT requiere revisar su régimen normativo, desde su expreso reconocimiento en la normativa internacional y comunitaria hasta las disposiciones específicas del régimen ibérico. Ello nos obliga a hacer una inexcusable alusión, por un lado al Convenio de Espoo por la especial importancia y trascendencia que ha supuesto en el sistema internacional y su repercusión en los sistemas nacionales, y por otro la Directiva EIA, determinante en el marco jurídico ibérico. En el ámbito nacional analizaremos los requerimientos y especificidades de los procedimientos de EIA de los sistemas nacionales de Portugal y España teniendo en cuenta la legislación 
aplicable al período de consultas analizado y con referencia a los últimos cambios operados en los sistemas de EIA de ambos países.

\subsection{La regulación en el ámbito internacional y comunitario}

En el Derecho internacional, la participación pública en el ámbito del medio ambiente, comienza a plasmarse en convenciones internacionales a partir de la década de los setenta del siglo XX hasta llegar a la trascendental Declaración de Rio de 1992 y su principio 104, dedicado a la participación pública. A partir de aquí empezaría a fraguarse la idea de que la solución de los problemas ambientales implicaba un cambio de los valores y percepciones de la sociedad, y esto sólo era posible con la implicación del público en general.

Desde entonces, esta idea de participación del público iría calando en declaraciones y convenios internacionales, y así sería incorporada en el Convenio sobre evaluación del impacto en el medio ambiente, en un contexto transfronterizo, de 25 de febrero de 1991, conocido como Convenio de Espoo. El Art. 2 del citado convenio introdujo el principio de igualdad de derechos de participación en los procesos de Evaluación de Impacto Transfronterizo (EIAT), reconociendo la equiparación de los ciudadanos de la Parte afectada a los de la Parte de origen. Ahora bien, la participación pública ambiental de la Declaración de Río de Janeiro tuvo su mayor despliegue y reconocimiento en el Convenio de la Comisión Económica para Europa (CEPE) sobre el acceso a la información, la participación del público en la toma de decisiones y el acceso a la justicia en materia de medio ambiente, de 25 de junio de 1998, conocido como Convenio de Aarhus. Entre los objetivos del Convenio de Aarhus destacaba la obligación de garantizar los derechos de la participación del público en la toma de decisiones en asuntos medioambientales para contribuir a la protección del derecho a vivir en un medio ambiente adecuado para la salud y el bienestar de las personas ${ }^{5}$.

\footnotetext{
${ }^{4}$ Este principio establece que: "El mejor modo de tratar las cuestiones ambientales es con la participación de todos los ciudadanos interesados, en el nivel que corresponda. En el plano nacional, toda persona deberá tener acceso adecuado a la información sobre el medio ambiente de que dispongan las autoridades públicas, incluida la información sobre los materiales y las actividades que encierran peligro en sus comunidades, así como la oportunidad de participar en los procesos de adopción de decisiones. Los Estados deberán facilitar y fomentar la sensibilización y la participación de la población poniendo la información a disposición de todos. Deberá proporcionarse acceso efectivo a los procedimientos judiciales y administrativos, entre éstos el resarcimiento de daños y los recursos pertinentes."(UNCED, 1992, p. 5).

${ }^{5}$ El artículo 6 del Convenio de Aarhus establece disposiciones en relación con la participación del público en las decisiones sobre las actividades específicas enumeradas en su anexo I y sobre las actividades no enumeradas
} 
La regulación de la EIA fue incorporada al ordenamiento comunitario inicialmente a través de la Directiva 85/337/CE, que estableció por primera vez un principio de participación pública transfronteriza, si bien restringido al público interesado y dejando reservada a los Estados Miembros la competencia respecto a la organización de los procesos participativos. La ratificación por la Unión Europea (UE) del Convenio de Espoo llevó a que la Directiva 97/11/CE, que modificaría la Directiva EIA de 1985, incorporase las reglas de Espoo al derecho europeo.

Las posibilidades de participación previstas según la normativa comunitaria han diferido de lo que había contemplado el Convenio de Espoo de 1991. Éste como convenio multilateral de referencia establece, entre otras cosas, que la "parte de origen" (aquella en cuya jurisdicción se ha de llevar a cabo una actividad propuesta) tiene que brindar al público, en las zonas susceptibles de ser "partes afectadas" (aquellas que tienen la probabilidad de verse afectadas por los efectos transfronterizos de una actividad propuesta), la oportunidad de participar en los procedimientos pertinentes de evaluación de impacto medioambiental de las actividades propuestas, así como velar porque esta oportunidad sea equivalente a la ofrecida al público de la parte de origen ${ }^{6}$. El "público" de Espoo es un concepto más amplio y comprensivo, "una o más personas físicas o jurídicas", sin establecer tampoco lo que debe entenderse por público interesado. La participación pública en el Convenio se deja abierta al público, entendido de forma general, situación que puede corroborarse en otras citas textuales referidas al público de las zonas que podrían verse afectadas, respecto a la recepción de información y la oportunidad de formular observaciones o plantear objeciones con respecto a la actividad propuesta ${ }^{7}$. A la luz de sus disposiciones, el Convenio no plantea dudas, pues no contempla la noción restrictiva de "interesado" ni la de "concernido" que hasta entonces se venía empleando en el ámbito comunitario.

A pesar de la claridad meridiana con que Espoo reconocía el principio de igualdad del público, la normativa comunitaria mantuvo las referencias específicas al público concernido en el ámbito de las consultas ambientales transfronterizas, y no al público en general. La UE, tras la firma y ratificación del Convenio de Aarhus, incorporó al ordenamiento comunitario los dictados del convenio a través de la “Directiva 2003/4/CE, de 28 de enero de 2003, sobre

que puedan tener un efecto significativo sobre el medio ambiente. Convenio sobre el acceso a la información, la participación del público en la toma de decisiones y elacceso a la justicia en materia de medio ambiente (CEPE, 2005, p. 5539).

${ }^{6}$ Ver artículo 2.6 del Convenio del Espoo.

${ }^{7}$ Ver artículo 3.8 del Convenio del Espoo. 
el acceso del público a la información ambiental" y la "Directiva 2003/35/CE, de 26 de mayo de 2003, por la que se establecen medidas para la participación del público en determinados planes y programas relacionados con el medio ambiente". Esta nueva modificación de la Directica EIA traería consigo la definición de los conceptos de público y público interesado, manteniendo la restricción de participación en las consultas transfronterizas a este público interesado. En consecuencia, España y Portugal ${ }^{8}$ estuvieron obligados a transponer a sus ordenamientos internos este marco jurídico sobre participación pública que incorporaba los dictados de los convenios de Espoo y Aarhus.

La Directiva EIA de 1985 y sus sucesivas modificaciones no exigieron formas de participación de tipo orgánica, sino funcional, siendo su objetivo posibilitar la formulación de alegaciones y posturas que complementasen la información disponible. La ratio iuris para esta incorporación de la participación consistía en otorgar presencia y voz a los ciudadanos cuyos intereses y visiones sectoriales normalmente no eran tenidas en cuenta, e hiciesen funcional y eficaz su intervención en la gestión de asuntos que conciernen a su entorno. Sin embargo la previsión comunitaria ha adolecido de imprecisión respecto a la organización del proceso de participación, quedando a la discrecionalidad de los Estados miembros aspectos clave como la determinación del público con derecho a participar, los mecanismos de notificación y consulta, los plazos o las formas que deberían adoptar las alegaciones y comentarios.

La distinta forma de materializar la titularidad del derecho y los mecanismos de participación, en algunos casos más abiertos y más proactivos que en otros, llevó a unas consecuencias desiguales entre los Estados miembros. Así, el informe de la Comisión al Parlamento Europeo y al Consejo sobre la aplicación y eficacia de la Directiva EIA titulado "Qué avances han realizado los Estados miembros sobre la aplicación de la Directiva de Evaluación de Impacto Ambiental" de $2003^{9}$, constataba que en la UE el público tenía oportunidad de opinar sobre los proyectos sujetos a la EIA, aunque el grado de participación del público era muy variable entre los países.

\footnotetext{
${ }^{8}$ España llevaría a cabo la transposición de dichas Directivas al ordenamiento interno a través de la Ley 27/2006, de 18 de julio, por la que se regulan los derechos de acceso a la información, de participación pública y de acceso a la justicia en materia de medio ambiente; y Portugal a través de la Lei 19/2006, de 12 de Junho . ${ }_{9}$ Informe de la Comisión Europea, de 23 de junio de 2003, consultado en: http://eur-lex.europa.eu/legalcontent/ES/TXT/?uri=CELEX:52003DC0334
} 
Más recientemente, el texto de la Directiva 2011/62/UE que vino a codificar la versión originaria de la Directiva y sus sucesivas modificaciones, tampoco ha mejorado el régimen de participación en las consultas ambientales. En el artículo $6^{10}$ de la DIrectiva EIA empleaba dos conceptos diferenciados de público -público interesado y público en general-, otorgándoles un tratamiento distinto en función de si se trata del derecho al acceso a la información, respecto al público en general, y del derecho a participación, restringido al público interesado. Los alcances de ambos conceptos revisten suma importancia para el derecho de participación en las actuaciones transfronterizas. El texto actual de la directiva ha mantenido vigentes las disposiciones de la antigua redacción de la derogada Directiva Impacto y por ello siguen sin estar resueltas las indefiniciones en este sentido. En el artículo 7 relativo a los "impactos transfronterizos" se mantiene la definición de "público concernido en el territorio del Estado miembro que pueda verse afectado de forma significativa"11 $\sin ^{\prime \prime}$ incorporar una definición y manteniendo su restricción a que se produzca un impacto ambiental de carácter significativo.

En cuanto a las fórmulas de información al público, la directiva prevé una serie de ejemplos ${ }^{12}$ como la colocación de carteles en un radio determinado, la publicación de avisos

${ }^{10}$ El Art 6.2. relativo a la puesta a disposición de información al público consta: "Se informará al público, mediante avisos públicos u otros medios apropiados, como los electrónicos cuando se disponga de ellos, de los siguientes asuntos desde una fase temprana de los procedimientos de toma de decisiones medioambientales contemplados en el artículo 2, apartado 2, y, como muy tarde, en cuanto sea razonablemente posible facilitar información....".; y en el apartado 3 del mismo artículo se refiere a la información dirigida al público interesado: "Los Estados miembros garantizarán que, dentro de unos plazos razonables, se pongan a disposición del público interesado los elementos...". Directiva 2011/92/UE de 13 de diciembre de 2011, relativa a la evaluación de las repercusiones de determinados proyectos públicos y privados sobre el medio ambiente, DOCE, 28 de enero de 2012, L 26/5.

${ }^{11}$ Ver art 7.3. de la Directiva: "Los Estados miembros concernidos, cada uno en la medida en que le incumba, tendrán también que: a) disponer lo necesario para que la información mencionada en los apartados 1 y 2 se ponga a disposición durante un plazo de tiempo razonable, de las autoridades mencionadas en el artículo 6 , apartado 1, y del público concernido en el territorio del Estado miembro que pueda verse afectado de forma significativa...". Esta referencia al "público concernid"o en el estado afectado -que no tiene definición legal alguna en la presente directiva- contrasta con la referencia a la "público interesado" que se establece en el apartado en el apartado 5; "Los Estados miembros interesados podrán determinar las modalidades de aplicación del presente artículo, que deberán permitir que el público interesado del Estado miembro afectado pueda participar efectivamente en los procedimientos de toma de decisiones medioambientales...". Directiva 2011/92/UE de 13 de diciembre de 2011, relativa a la evaluación de las repercusiones de determinados proyectos públicos y privados sobre el medio ambiente, DOCE, 28 de enero de 2012, L 26/5.

${ }^{12} \mathrm{El}$ art. 6.5 de la actual Directiva EIA establece: "Las modalidades de información al público (por ejemplo, mediante la colocación de carteles en un radio determinado, o la publicación de avisos en la prensa local) y de consulta al público interesado (por ejemplo, mediante el envío de notificaciones escritas o mediante una encuesta pública) serán determinadas por los Estados miembros." Directiva 2011/92/UE de 13 de diciembre de 
en la prensa local; y de consulta al público interesado, como el envío de notificaciones escritas o encuestas públicas. España y Portugal no fueron ajenas a estas consecuencias de la autonomía que había permitido la Directiva EIA.

\subsection{La regulación en España y Portugal}

En Portugal, la transposición al ordenamiento interno de las reglas de Espoo adoptadas por la Directiva 97/11/CE se llevó a cabo con ciertas deficiencias y retrasos. Estas deficiencias se produjeron debido a que la primera legislación sobre EIA había sido adoptada en 1990, a través del Decreto-Lei 186/90, de 6 de junio, si bien no había incorporado lo dispuesto en el Art. 7 de la directiva relativo a las consultas transfronterizas. Así la obligación legal de la notificación transfronteriza no sería incorporada al orden interno portugués hasta que se aprobó el siguiente regimen de EIA (Arts. 32 a 35 del Decreto-Lei 69/2000, de 3 de mayo), con un año de retraso respecto al plazo de transposición de la directiva.

En España, la transposición de las disposiciones comunitarias sobre EIAT fueron incorporadas al año siguiente de la aprobación de la Directiva EIA mediante el Real Decreto Ley 1302/1986, de 28 de junio, y la modificación de la Directiva de 1997 que contenía las reglas de Espoo se llevó a cabo en 2001 a través del Real Decreto Ley 6/2001, de 6 de octubre (Art. 6), también con retraso respecto al plazo máximo de transposición previsto.

En la regulación del procedimiento de EIAT de España y Portugal la titularidad del derecho de participación se presenta restringido a las administraciones afectadas y al público interesado -y no abierto a todo el público-. Ambas legislaciones establecen previsiones específicas en relación con la necesidad de realizar consultas al público interesado, además de a las autoridades públicas afectadas, en caso de que se aprecien potenciales efectos transfronterizos. En España como público interesado ${ }^{13}$ se entiende aquellos titulares de

2011, relativa a la evaluación de las repercusiones de determinados proyectos públicos y privados sobre el medio ambiente, DOCE, 28 de enero de 2012, L 26/5.

${ }^{13} \mathrm{El}$ art 5.1.g) contempla la siguiente definición: "«Personas interesadas»: se consideran interesados en el procedimiento de evaluación ambiental: 1. Todos aquellos en quienes concurran cualquiera de las circunstancias previstas en el artículo 31 de la Ley 30/1992, de 26 de noviembre, de Régimen Jurídico de las Administraciones Públicas y del Procedimiento Administrativo Común. 2. Cualesquiera personas jurídicas sin ánimo de lucro que, de conformidad con la Ley 27/2006 de 18 de julio de acceso a la información, de participación pública y de acceso a la justicia en materia de medio ambiente, cumplan los siguientes requisitos: i) Que tengan, entre los fines acreditados en sus estatutos la protección del medio ambiente en general o la de 
derechos e intereses afectados por la decisión según el art. 31 Ley 30/92 ${ }^{14}$. En Portugal, el Decreto-Lei 151-B/2013 define al público interesado como aquellos titulares de derechos o de intereses afectados por la decisión del procedimiento de EIA o público susceptible de ser afectado por la decisión (art. 2 r) ${ }^{15}$.

Como podemos observar en la tabla 1, los diversos conceptos legales relativos a público y público interesado que se contemplan a nivel nacional y transfronterizo atribuyen una distinta legitimación para participar en el procedimiento de EIA, en su fase nacional y transfronteriza. De acuerdo con la legislación interna, en ambos procedimientos nacionales de EIA se reconoce el derecho de información del público y una participación limitada y selectiva de un sector del público -asociaciones ambientales, ONGs y público interesado-. A esta restricción hay que añadir, en el ámbito de la consulta transfronteriza, la condición previa de que el Estado afectado pueda resultar significativamente afectado.

En los procedimientos nacionales de EIA existen dos modalidades de participación pública, una abierta, de información, y otra restringida, de consultas y participación, que tienen lugar en 3 fases diferentes del procedimiento como se describe en la figura 1. Como observamos la fase de consultas y participación, restringida a la categoría de interesados y personas y entidades que hubiesen participado en la fase previa de determinación del alcance, tiene lugar en trámite simultáneo al de exposición de la información al público.

En cuanto a las modalidades de información y consulta, el legislador español y portugués adoptaron en la fase nacional y transfronteriza mecanismos tradicionales: publicación de

alguno de sus elementos en particular, y que tales fines puedan resultar afectados por la evaluación ambiental. ii) Que lleven, al menos, dos años legalmente constituidas y vengan ejerciendo, de modo activo, las actividades necesarias para alcanzar los fines previstos en sus estatutos. iii) Que según sus estatutos, desarrollen su actividad en un ámbito territorial que resulte afectado por el plan, programa o proyecto que deba someterse a evaluación ambiental". (Ley 21/2013, de 9 de diciembre, de evaluación ambiental, BOE, Núm. 296, 11 de diciembre de 2013, p. 98163).

${ }^{14}$ Sin embargo tal como refiere García-Álvarez García (2013, p. 440) en los procedimientos en los que se abre una fase de información pública sí se otorga un derecho, aunque meramente formal, a los alegantes en una información pública al amparo del art. 86.3 párrafo segundo de la Ley 30/92: “No obstante, quienes presenten alegaciones u observaciones en este trámite tienen derecho a obtener de la Administración una respuesta razonada, que podrá ser común para todas aquellas alegaciones que planteen cuestiones sustancialmente iguales". (Ley 30/1992, de 26 de noviembre, de Régimen Jurídico de las Administraciones Públicas y del Procedimiento Administrativo Común, BOE, 27 noviembre 1992, núm.285, p. 40313).

${ }^{15} \mathrm{El}$ art. 2 r) establece la definición: “"Público interessado», os titulares de direitos subjetivos ou de interesses legalmente protegidos, no âmbito das decisões tomadas no procedimento administrativo de AIA, bem como o público afetado ou suscetível de ser afetado por essa decisão, designadamente as Organizações NãoGovernamentais de Ambiente (ONGA)". (Decreto-Lei n.o 151-B/2013 de 31 de outubro, Diário da República, 31 de outubro de 2013 , N.o 211, p. 6328-8). 
anuncios en boletines oficiales, periódicos de difusión nacional, y puesta a disposición de la documentación ambiental en las sedes de las administraciones territoriales y organismos oficiales. Ambos sistemas basan la participación pública en la revisión del Estudio de Impacto Ambiental (Es|A), y en una posterior presentación de comentarios y alegaciones, por escrito y sin posibilidad de diálogo alguno con el promotor.

\subsection{Los cambios legislativos en los sistemas de EIA de España y Portugal}

Los nuevos regímenes sancionados en al año $2013^{16}$ en ambos países no han introducido cambios importantes en la regulación de los procesos de participación nacionales y transfronterizos.

En España los mecanismos de participación, plazos, lugares de exposición y demás aspectos de la organización de la participación transfronteriza se remiten a las disposiciones sobre la participación nacional de las administraciones públicas afectadas y público interesado (Arts. 37-49). La organización de las consultas compete a la administración sustantiva que somete a información pública el proyecto y el EsIA, y practica la notificación a las administraciones públicas afectadas y las personas interesadas a fin de que puedan participar formulando alegaciones. La notificación deberá contener el EsIA o el lugar donde puede ser consultado, la designación del órgano al que se deben remitir los informes y toda aquella otra documentación relevante del proyecto. El medio empleado es la notificación, si bien no se establecen mecanismos concretos de cómo llevarla a cabo: si por carta, correo electrónico, u otro medio. Sin embargo, la nueva regulación ha introducido que se podrá realizar por medios convencionales, electrónicos o cualesquiera otros, siempre que se acredite la realización de la consulta. En cuanto al plazo para formular alegaciones, éste será de un máximo de 30 días hábiles desde la recepción de la notificación para emitir los informes.

En el caso de Portugal, la previsión sobre participación en las consultas transfronterizas es también parca. En cuanto a los sujetos que pueden participar, también está restringida al público interessado e a todas as autoridades a quem o projeto possa interessar (Art. 35.1). El

\footnotetext{
16 En España, Ley 21/2013, de 9 de diciembre, de evaluación ambiental. Boletín Oficial del Estado, 11 de diciembre de 2013, núm. 296, p. 98151 a 98227; en Portugal, Decreto-Lei n.o 151-B/2013 de 31 de outubro, Diário da República, 31 de outubro de 2013, 1.a série, núm. 211, 6328-(6-31).
} 
desarrollo de las consultas en Portugal se ajusta a los mismos requisitos que los establecidos para la participación en la fase de consultas internas. La entidad responsable de desencadenar el procedimiento de consultas es la Autoridad de Impacto Ambiental - AIA, la Agencia Portuguesa do Ambiente, o según el caso, las Comissões de Coordenação e Desenvolvimento Regional (CCDR). Constrasta, respecto al procedimiento en España, la intervención de la Comisión de Evaluación (CA), que como comité mixto y específico en el que están representadas las administraciones públicas sectoriales, el promotor y expertos, se encarga de verificar la conformidad y la valoración técnica del Estudio de Impacto Ambiental (EsIA) y de elaborar el informe de consulta pública. Realizado este informe de consulta pública, los resultados de participación son enviados por vía diplomática a España para su incorporación y valoración en España. La decisión final de conclusión del procedimiento en España, una vez notificado por éste, deberá ser divulgada a través de los medios electrónicos sempre que possível.

Esta nueva regulación deja a la autoridad ambiental portuguesa, la AIA, la forma de concretar el mecanismo de consulta a adoptar en cada caso en función de la naturaleza, complejidad del proyecto, sus impactos o su grado de conflictividad potencial a fin de que ello permita uma efetiva auscultação do público interessado. La mención expresa a una efectiva consulta parece conectar con el objetivo deseado y comentado por la literatura sobre la participación a la que nos hemos referido anteriormente. Respecto a los resultados de la consulta pública, la ley portuguesa ha descendido a detallar su contenido, al exigir una descripción de los medios y formas elegidas para la publicación del proyecto y participación, y una síntesis de las opiniones predominantemente expressas e a respetiva representatividade. También ahora con el objeto de introducir más transparencia y accesibilidad se ha creado un portal único, balcão único eletrónico, que centraliza la información relativa al proceso. En este sentido también se precisa que durante el período de consultas el EsIA y el Resumen no Técnico (RNT) deberán estar disponibles en la local de la AIA; las CCDR y las câmaras municipales del área de localización del proyecto. El plazo de consulta es de 20 días, o 15 si se trata de proyecto sometido a licencia industrial. 


\section{La participación pública en el derecho comparado}

Los sistemas más avanzados en EIA han planteado una variedad de propuestas de mecanismos de participación orientados a la transparencia y la involucración del público. En esta senda se encuentran los países con más tradición en EIA como EEUU y Canadá y otros países desarrollados en el continente europeo como Reino Unido, Francia, Holanda o Dinamarca. Una revisión de la práctica que siguen sus procesos participativos pone de manifiesto fórmulas que se podrían considerar los actuales estándares de participación pública en EIA.

En el caso de los EEUU, la práctica es muy reveladora ya que al público más que informarle, se le invita a participar en las consultas a través de un sistema basado en notificaciones que se realizan por una gran variedad de cauces. Los mecanismos abiertos se adoptan desde las primeras fases del procedimiento y entre éstos se contemplan desde la conversación teléfonica, o las reuniones comunitarias, hasta alegaciones por escrito que se pueden presentar tanto on line como en papel. Los mecanismos de consulta más frecuentemente utilizados en la fase de examen del EsIA son los public hearings y los grupos de asesoramiento del público, community advisory groups (Beirele and Cayford, 2002; Zavestoski and Shulman; 2006). Sin embargo, los análisis de estos casos destacan que los EsIA son con frecuencia documentos muy complejos y técnicos que difícilmente son comprensibles para el ciudadano medio a pesar de los mecanismos abiertos que se adoptan (Sullivan et al., 1996) Los public hearing tienen lugar en general en lugares de cierta asiduidad de público o en sitios céntricos de las ciudades, aunque alejados de la localización del proyecto en cuestión. Estos factores han ocasionado efectos disuasorios respecto a determinados sectores del público deslocalizados de estos lugares de celebración o de bajos recursos económicos.

En Reino Unido, se utiliza también una variedad de métodos de participación cuya determinación queda a elección de los promotores del proyecto teniendo en cuenta la naturaleza del mismo. Entre estos se contemplan desde los más tradicionales como la exposición pública, boletínes informativos y noticias en periódicos locales, hasta los más informales y abiertos como las presentaciones informales, reuniones públicas, comités de asesoramiento público y encuestas públicas (Petts, 2003; Hartley and Wood, 2005). Tal 
como afirma Wood (2003) la elección de cualquiera de esta variedad de métodos en este sistema es posible porque las consultas y las técnicas de participación no descansan en condicionamientos legales previos.

El modelo canadiense se caracteriza por anticipar todo lo posible la consulta para garantizar que la participación se produzca en las fases iniciales y así se eviten retrasos posteriores. A pesar de ello, la adopción de los mecanismos de consulta, como las public hearings, quedan a la elección del llamado comité de revisión nacional que en el caso de afectar a varias jurisdicciones se constituye conjuntamente: joint review panel (Art. 40, Environmental Assessment Act, 2012). La incorporación de este panel de expertos conlleva la articulación de mecanismos de participación pública de gran complejidad y duración. Destacan en este sistema otros dos aspectos muy caracterizadores, el programa de apoyo financiero para facilitar la participación, participant funding program, que el gobierno federal destina a facilitar la involucración del público; y el gran protagonismo que se otorga al promotor respecto a la planificación de las consultas a través del Proponent's Public Involvement Program. El sistema canadiense es considerado uno de los más efectivos por la influencia de la participación del público afectado, llegando a menudo a provocar cambios en el proyecto sometido a consultas (Sinclair and Diduck, 2001).

Holanda también se caracteriza por proveer de información al público desde su inicio hasta la fase de seguimiento del proyecto. En la práctica, las consultas públicas tienen lugar en dos fases, la de determinación de alcance y durante la fase de examen del EsIA. Para cada una de ellas se concede un plazo de de 4 semanas para presentar las alegaciones. No existen programas de apoyo económico de la participación ni para el traslado de sectores públicos a los lugares de reunión, sin embargo en algunos casos asociaciones y grupos ambientales son subvencionados para contar con su presencia en determinados casos de EIA. En este sistema, el resultado de la celebración de las public hearings se presenta a una comisión independiente de la EIA, conocida como panel review. Las autoridades competentes publican cómo las alegaciones han influenciado en la toma en consideración de las alternativas y en el proyecto. También se envían copias de la decisión adoptada a los participantes de los public hearings, a todos los que debían ser consultados y a miembros de la comisión de la EIA (Petts, 1999; Wood, 2003). 


\section{Análisis de la participación en las consultas transfronterizas entre España y Portugal}

El análisis de los casos más recientes de proyectos sometidos a consulta transfronteriza en ambos países durante período 2008-13 alcanza los 7 casos en Portugal y 6 en España (tabla 2).

Respecto al cumplimiento del trámite de información pública se observa que en todos los procesos de consultas se ha verificado un sistemático cumplimiento de los principios de transparencia y publicidad porque se remitieron consultas directamente a las administraciones públicas afectadas y se publicó información sobre las características más significativas del proyecto para facilitar la participación del público interesado. La información pública en cumplimiento de las disposiciones de cada país tuvo lugar por los canales establecidos según la normativa de cada país: a) exposición en lugares públicos; b) acceso público en internet en el site de la APA -Agencia Portuguesa de Ambiente- y del MAGRAMA -Ministerio de de Agricultura, Alimentación y Medio Ambiente-; y c) publicación de anuncios en boletines oficiales y en diarios dando cumplimiento a lo establecido al respecto por la legislación nacional de ambos países ${ }^{17}$.

En cuanto al análisis de los datos de participación pública de los -Informes nacionales de consulta transfronteriza- se observa que respecto a los 7 procesos de consultas EIAT tramitados en Portugal no ha habido ninguna alegación de particulares, y las consultas a las administraciones afectadas solo han obtenido respuestas en un $27 \%$ de las consultas enviadas. En muchos casos éstas han sido de escaso valor desde el punto de vista ambiental

\footnotetext{
${ }^{17}$ En Portugal la regulación respecto a la información pública estaba regulada por el artículo 29.3 del DecretoLei n.o 151-B/2013 establece respecto a las modalidades de información: "Compete à autoridade de AIA decidir, em funçãoda natureza e complexidade do projeto, dos seus impactes ambientais previsíveis, ou do grau de conflitualidade potencialda sua execução, a forma de concretização adequadada consulta pública que permita uma efetiva auscultação do público interessado." (Decreto-Lei n. 151-B/2013 de 31 de outubro, Diário da República, 31 de outubro de 2013, N.o 211, p. 6328-16). En el caso de España la Ley 21/2013, de 9 de diciembre, de evaluación ambiental establece en el artículo 22 punto 1: “...La consulta a las Administraciones públicas afectadas y a las personas interesadas se podrá realizar por medios convencionales, electrónicos o cualesquiera otros, siempre que se acredite la realización de la consulta." (Ley 21/2013, de 9 de diciembre, de evaluación ambiental, BOE, núm. 296, 11 de diciembre de 2013, p. 98172).
} 
(tabla 3). En sólo dos casos se han registrado alegaciones transfronterizas que se han tenido en consideración: el caso de la Refinería de Balboa - 2008 (España) y el caso de la Explotación minera en Río Manzanas -2009 (España). En este último caso las autoridades portuguesas, al objeto de dar respuesta a las insuficiencias identificadas en las informes suministrados, reclamaron información adicional para identificar y evaluar los impactos en territorio portugués. En el referido proyecto de la Refinería de Balboa la consideración de las alegaciones portuguesas sobre los posibles impactos transfronterizos significó una ampliación de la descripción del estudio del promotor y que se realizase una evaluación de unos riesgos que no habían sido contemplados inicialmente. La respuesta española a estos requerimentos no fue satisfactoria para el estado portugués y causó el malestar de las autoridades portuguesas, llevando a que se celebrase una reunión por este motivo ${ }^{18}$. Solo en estos casos donde la afectación transfronteriza ha sido puesta de manifiesto de forma ostensible se observan cambios de posición y tomas en consideración por el estado de origen.

En las consultas transfronterizas realizadas en España (tabla 4) se observa también que la participación ha sido inexistente en el caso del público interesado, presentando un índice muy bajo, un $28 \%$, de respuesta de las administraciones afectadas consultadas. En casos como Aprovechamiento hidroeléctrico de Bemposta - 2007 (Portugal) y Conexión ferroviaria AVE Elvas-Caia - 2009 (Portugal) no se presentaron en plazo, y en otros como en Conexión ferroviaria Ave Oporto/Vigo - 2009 (Portugal) han sido de escasa consideración, no constando en este caso cómo han sido efectivamente integradas.

\footnotetext{
${ }^{18}$ La Agencia Portuguesa do Ambiente con fecha 5 de mayo de 2009 envió a Esapña el resultado de la información pública realizada en territorio portugués, con el parecer de Portugal sobre el impacto transfronterizo de la Refinería Balboa. En este informe, las Autoridades Portuguesas exponen unas consideraciones referidas, fundamentalmente, a la necesaria adecuación del vertido de la refinería. Tres meses más tarde, el 3 de agosto de 2011, se remitiría a la Agencia Portuguesa do Ambiente un documento elaborado por el promotor, traducido al portugués, donde se contemplaba la manera en que habían sido tenidas en cuenta las manifestaciones por Portugal hechas a lo largo de la tramitación. A pesar de ello, la Ministra do Ambiente e do Ordenamento do Território del Gobierno de la República Portuguesa con fecha de 25 de agosto de 2011 reiteraría su preocupación por cómo habían sido resueltas las cuestiones planteadas por su país durante la tramitación, al tiempo que exponía las inquietudes acerca de los posibles impactos del proyecto sobre territorio portugués. (Declaración de Impacto ambiental del proyecto "Construcción de una refinería de petróleo en Extremadura, término municipal de Los Santos de Maimona -Badajoz-, y sus infraestructuras asociadas -Sevilla y Huelva-", Boletín Oficial del Estado, núm. 181, 30 de julio de 2012. p. 54698. Disponible en: https://www.boe.es/boe/dias/2012/07/30/pdfs/BOE-A-2012-10244.pdf)
} 
A pesar de esta diversidad en la modalidades de propocionar información y del considerable número de consultas dirigidas a las administraciones públicas previsiblemente afectadas y público interesado, solo en muy pocos casos se han presentado respuestas con alegaciones; y de éstas, no todas contienen apreciaciones de suficiente significación y consistencia para ser tenidas en cuenta. En parte, esto sugiere que la consideración e integración de las mismas por el Estado de origen ha sido testimonial. Según se deduce de la información facilitada por la APA portuguesa y la Subdirección General de Evaluación Ambiental española, no ha habido notificación de los pronunciamentos ambientales recaídos ni de las decisiones finales sobre los proyectos al país vecino. Esto pone en tela de juicio la efectividad de las consultas puesto que el Estado afectado y sus nacionales no pueden comprobar la toma en consideración de sus comentarios.

A la luz de los casos analizados en los proyectos sometidos a consultas transfronterizas, la involucración del público del país vecino es inexistente, lo cual pone en entredicho la participación pública real y efectiva que constituye el objetivo último de la consulta ambiental transfronteriza. Esto sugiere que el trámite de consultas transfronterizas ha quedado relegado en muchos casos a un mero trámite burocrático de información con limitadas consecuencias. Por otro lado se observa que la integración y ponderación de las alegaciones no se realiza de forma clara y expresa en las declaraciones ambientales del país afectado. A esto hay que añadir la subsistencia en casi todos los proyectos del incumplimiento por no comunicar las DIA recaídas, lo cual no permite que la opinión pública del estado afectado pueda hacer un seguimiento de cómo se han incorporado sus alegaciones.

Los mecanismos de los procesos participativos desarrollados en España y Portugal distan mucho de los modelos de sistemas avanzados de EIA a los que nos hemos referido anteriormente. La participación que se ha registrado ha sido como respuesta a las consultas institucionales por parte de las administraciones públicas sectoriales en cada país. La mera puesta a disposición del EsIA y de los resúmenes no técnicos en las sedes electrónicas y sedes de las autoridades ambientales y organismos públicos parecen no ser los medios apropiados para alcanzar a los posibles afectados y tampoco parecen ser suficientes para despertar el interés del público interesado. 
En contraste a lo que sucede en el contexto ibérico, los sistemas de participación en EIA de otros países desarrollados incorporan mecanismos más abiertos, más informales y más adaptados a la necesidad del caso concreto. Por otro lado, los medios que se han empleado para dar a conocer la información ambiental y el proyecto -anuncios en los boletines oficiales, y diarios nacionales e información ambiental accesible en las sedes de administraciones públicas territoriales de cada país- contrastran con los que se emplean en países como Holanda, Canadá y EEUU que eligen mecanismos para informar y determinar el tipo de público posiblemente afectado, mediante una variedad de formas y en multitud de lugares. Los exiguos plazos establecidos para la participación en las consultas ibéricas -30 días en España y 20 en Portugal- también difieren de los plazos estándares de estos países. Es ilustrativo el modelo francés ${ }^{19}$ que organiza los llamados "debat public", en los que los plazos para participar se dimensionan dependiendo de la naturaleza y necesidades de cada proyecto; o en el caso canadiense ${ }^{20}$, que incorpora mecanismos garantistas a través del "Joint Review Panel" ejerciendo una función de control tanto sobre la autoridad administrativa como el promotor a fin de que la participación sea efectiva en cada proyecto.

Este tipo de mecanismos también se apuntan en la más reciente guía de interpretación del Convenio de Aarhus, las Recomendaciones de Maastrichts (CEPE, 2014), destinadas a fomentar la participación pública efectiva en la toma de decisiones en asuntos medioambientales. En este documento se propone la adopción de mecanismos más abiertos en la participación en la EIA: métodos de notificación al público mediante mecanismos lo más amplios posibles y teniendo en cuenta la naturaleza de cada proyecto. Así se proveen una serie de medidas de notificación como las llamadas a la puerta en los casos de ciudadanos que carezcan de teléfono o electricidad; oportunidades de participación anticipadas, antes de la elaboración de las alternativas y en la llamada fase de scoping; así como orientaciones imparciales al público por parte de expertos a fin de facilitar

\footnotetext{
${ }^{19}$ En Francia la utilización de los mass media y de las nuevas tecnologías de la información y comunicación son una práctica habitual en la organización de los denominados "Debat public". i.e: Projet de Ligne Nouvelle ParisNormandie. Online: http://cpdp.debatpublic.fr/cpdp-Inpn/

${ }^{20}$ El Canadá se utilizan los llamados "Joint Review Panel" como paneles de expertos que garantizan el control del procedimiento de participación pública. Art 38 y ss Canadian Environmental Assessment Act, 2012. Online: http://laws-lois.justice.gc.ca/eng/acts/c-15.21/page-11.html\#h-20
} 
la compresión y la concienciación de la importancia de participar en la consulta y su transcendencia para la toma de decisión.

\section{Conclusiones}

Desde el punto de vista jurídico, a pesar de los avances que se han introducido por la transposición comunitaria e internacional de las disposiciones del Convenio de Espoo y Aarhus, subsisten en la normativa de ambos países aspectos en los que la participación transfronteriza aún presenta limitaciones por la falta de adopción de fórmulas que verdaderamente se dirigan a la accesibilidad de la información y a la involucración del público. Los actuales estándares de participación transfronteriza en este contexto pecan de formalistas al no buscar de forma activa la integración de las alegaciones y opiniones del público del país afectado por lo que que debe producirse una evolución hacia la incorporación de nuevos mecanismos más abiertos y flexibles en ambos países.

El desarrollo de las consultas pone de manifiesto que en todos los casos se han respetado los plazos de puesta a disposición de la información y se han utilizado medios de publicidad que garantizan la transparencia y el acceso a la participación pública pero subsiste el problema de la falta de involucración pública y esto nos lleva a cuestionar si la información y la publicidad ofrecidas alcanzan e interesan al ciudadano de uno y otro país. Las modalidades de participación empleadas no son adecuadas para que el público pueda formarse una opinión, y que la misma se tenga en consideración en la decisión. La participación formal está asegurada pero ésta no es real y efectiva. Esto nos obliga a obtener respuesta a una serie de interrogantes: ¿̇e ha permitido la participación efectiva de este público no nacional? ¿en qué horario? ¿ha sido compatible con los horarios de los ciudadanos? ¿las ubicaciones han sido adecuadas para una consulta rigurosa y pausada? ¿han podido obtener copias debidamente traducidas? ¿podría contribuir la e-administación y otros mecanismos más interactivos mejorar la accesibilidad a la información en el futuro? ¿por qué no se ha notificado la DIA o resolución aprobatoria del país de rigen para comprobar la toma en consideración de las alegaciones transfronterizas? ¿la consideración de las alegaciones ha satisfecho las expectativas del público y de los consultados? Obtener 
respuesta a muchas de estas cuestiones requeriría adoptar un enfoque de investigación más amplio de base cualitativa que indague en las motivaciones de la participación del público en cuestiones ambientales, y no solo en sede de la EIA. Al mismo tiempo, es necesario evaluar cómo el interés de las autoridades públicas en la involucración del público, de uno y otro país influye en estos procesos.

En este sentido, hay que considerar que para el análisis de los índices de participación hemos recurrido a las fuentes y bases de datos que ofrecen respuestas objetivables aunque la cuestión clave para la determinación de la efectividad de las consultas en el contexto ibérico requiere la consideración de factores que se hallan más allá de la información proporcionada por estas fuentes. Así, debemos ponderar cuestiones que podrían estar arraigadas tanto en las respectivas idiosincrasias nacionales como en la propia sociología de la participación. Autores como Petts (1999) citan varios elementos inherentes a lo que se debe considerar como participación efectiva -el compromiso, la equidad, la comunicación y la confianza- y calificados todos ellos como dífíciles de verificar en cada caso concreto. Además, a la par de ello hay que considerar que "existe una diversidad de opiniones respecto a lo que debemos considerar participación pública efectiva" (Hartley and Wood, $2003)^{21}$. A pesar de que estas cuestiones tan cruciales emergen como condicionamientos en el resultado de estos análisis sobre participación, este estado de la cuestión no puede dejar de apuntar a la necesidad de que las administraciones asuman un papel más activo en las consultas ambientales transfronterizas.

\section{Bibliografía}

ANDRÉ, P., ENSERINK B., CONNOR D. and CROAL P. Public participation: International Best Practice Principles. Special Publication Series. 2006, No. 4. Fargo, USA: International Association for Impact. Disponible en: https://www.iaia.org/publicdocuments/special-publications/SP4\%20web.pdf

BEIERLE, TC. and CAYFORD, J. Democracy in practice: public participation in environmental decisions. Washington, DC., Resources for the Future , 2002.

BISSET, R. Methods of consultation and public participation. In: Lee N, George C, editors. Environmental impact assessment in developing and transitional countries: principles, methods and practice. New York: John Wiley and Sons; 2000.

\footnotetext{
${ }^{21}$ En el original: "... a variety of differing opinions prevail about what constitutes 'effective' public participation exists." (Hartley y Wood, 2005, p. 338).
} 
BRUCH, C., NAKAYAMA, M., TROELL, J., GOLDMAN, L., AND MARUMA MREMA, E. Assessing the Assessments: Improving Methodologies for Impact Assessment in Transboundary Watercourses. Water Resources Development, 2007, 23(3), 391-410.

CEPE. Comisión Económica para Europa de las Naciones Unidas. Convenio de la Comisión Económica para Europa de las Naciones Unidas sobre la evaluación del impacto ambiental en un contexto transfronterizo suscrito en Espoo (Finlandia) el 25 de febrero de 1991. Boletín Oficial del Estado, 31 de octubre de 1997, núm.

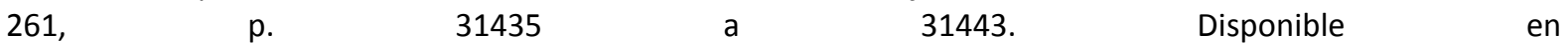
http://www.unece.org/fileadmin/DAM/env/eia/documents/legaltexts/conventiontextspanish.pdf

CEPE. Comisión Económica para Europa de las Naciones Unidas. Guidelines on public participation in transboundary EIA. (ECE/MP.EIA/7) $2006 . \quad$ Disponible en: http://www.unece.org/fileadmin/DAM/env/documents/2006/eia/ece.mp.eia.7.pdf

CEPE. Comisión Económica para Europa de las Naciones Unidas. Convenio sobre el acceso a la información, la participación del público en la toma de decisiones y el acceso a la justicia en materia de medio ambiente, hecho en Aarhus (Dinamarca), el 25 de junio de 1998. Boletín Oficial del Estado, 16 de febrero de 2005, núm. 40, p. 5535 a 5547. Disponible en: http://www.boe.es/buscar/doc.php?id=BOE-A-2005-2528

CEPE. Comisión Económica para Europa de las Naciones Unidas. Maastricht Recommendations on Promoting Effective Public Participation in Decision-making in Environmental Matters (ECE/MP.PP/2014/8). Meeting of the Parties, Fifth session, Maastricht, the Netherlands, 30 June and 1 July 2014. Disponible en: http://www.unece.org/fileadmin/DAM/env/pp/mop5/Documents/Post_session_docs/ece_mp.pp_2014_2_ad d.2_eng.pdf

CRAIK, N. The International Law of Environmental Impact Assessment. Cambridge University Press. 2008.

ESPAÑA. Ley 21/2013, de 9 de diciembre, de evaluación ambiental. Boletín Oficial del Estado, 11 de diciembre de 2013, núm. 296, p. 98151 a 98227.

ESPAÑA. Ley 30/1992, de 26 de noviembre, de Régimen Jurídico de las Administraciones Públicas y del Procedimiento Administrativo Común, Boletín Oficial del Estado, 27 noviembre 1992, Núm. 285, p. 40300 a 40319.

ESPAÑA-PORTUGAL. Protocolo de actuación entre el Gobierno del Reino de España y el Gobierno de la República Portuguesa de aplicación en las evaluaciones de planes, programas y proyectos con efectos transfronterizos, firmado en Madrid, el 19 de febrero de 2008. Disponible en: http://www.magrama.gob.es/es/calidad-y-evaluacion-ambiental/temas/evaluacion-

ambiental/2.Protocolo_de_Actuacion_Espa\%C3\%B1a_Portugal_tcm7-219903.pdf

FISCHER, TB., GAZZOLA, P., JHA-THAKUR. U., BELCAKOVA, I. and ASCHEMANN, R,. Editors. Environmental assessment lecturers' handbook. ROAD Bratislava, 2008.

FITZPATRICK, P. and SINCLAIR, A. J. Learning through Public Involvement in Environmental Assessment Hearings. Journal of Environmental Management. 2003, 67(2), p. 161-174.

FURIA, LD. and WALLACE-JONES, J. The effectiveness of provisions and quality of practices concerning public participation in EIA in Italy. Environmental Impact Assessment Review 2000, 20, p. 457-79.

GARCÍA-ÁLVAREZ, G. Acceso a la información, participación y acceso a la justicia en cuestiones ambientales: del Convenio de Aarhus a la sentencia Boxus", en Monografías de la Revista Aragonesa de Administración Pública, XIV, ISSN 1133-4797, XIV, Zaragoza, 2013, p. 433-472.

GAUTHIER, M., SIMARD, B, L. and WAAUB, J. Public participation in strategic environmental assessment (SEA): Critical review and the Quebec (Canada) approach. Environmental Impact Assessment Review. 2011, 31, p. 4860.

GLASSON, J., THERIVEL, R,. and CHADWICK, A. Introduction to environmental impact assessment. 3rd ed. London: Routledge; 2005.

HARTLEY, N., and WOOD, CM. Public participation in environmental impact assessment - implementing the Arhus Convention. Environmental Impact Assessment Review. 2005, 25, p. 319-40. Disponible en: http://www.unece.org/fileadmin/DAM/env/pp/documents/cep43s.pdf 
JAY, S., JONES, C., SLINN, P. and WOOD, C. Environmental impact assessment: retrospect and prospect. Environmental Impact Assessment Review. 2007, 27, p. 287-300.

KNOX, J. The Myth and Reality of Transboundary Environmental Impact Assessment. American Journal of International Law. 200296 (2), 291-319.

MARTÍNEZ OROZCO, J. El modelo español de participación pública en la evaluación de impacto ambiental: el largo camino hacia Aarhus. En Evaluación de impacto ambiental en España: nuevas perspectivas: (Actas del IV Congreso Nacional de Evaluación de Impacto Ambiental, IV CONEIA):[Madrid, abril 2007]. Asociación Española de Evaluación de Impacto Ambiental, 2008. p. 423-430.

OECD. Organisation for Economic Co-operation and Development. Citizens as partners: Information, consultation and public participation in policy-making. 2001. Disponible en: http://internationalbudget.org/wp-content/uploads/Citizens-as-Partners-OECD-Handbook.pdf

O'FAIRCHEALLAIGH, C. Public participation and environmental impact assessment: Purposes, implications, and lessons for public policy making, Environmental Impact Assessment Review. 2010, 30(1), p. 19-27.

PALERM, JR. An empirical-theoretical analysis framework for public participation in environmental impact assessment. Journal of Environmental Assessment Policy and Management 2000, 43, p. 581-600.

PALIWAL, R. EIA practice in India and its evaluation using SWOT analysis. Environmental Impact Assessment Review. 2006, 26, p. 492-510.

PETTS, J. Public participation and environmental impact assessment. In: Petts, J. ed. Handbook of environmental impact assessment: vol. 1. Environmental impact assessment: process, methods and potential. Oxford, Blackwell Science, 1999, p. 145-173.

PETTS, J. Barriers to deliberative participation in EIA: learning from waste policies, plans and projects. Journal of Environmental Assessment Policy and Management. 2003, 5, p. 269-293.

PORTUGAL. Decreto-Lei n. 151-B/2013 de 31 de outubro, Diário da República, 31 de outubro de 2013, 1. a série, núm. 211, 6328-(6-31).

ROWE, G. and FREWER, LJ. Evaluating public participation exercise: a research agenda. Science, technology \& human values, 2004, vol. 29, 4, p. 512-556.

SINCLAIR, J. and DIDUCK, AP. Public involvement in EA in Canada: a transformative learning perspective. Environmental Impact Assessment Review. 2001, 21, p. 113-136

SULLIVAN, WC., KUO, FE., and PRABHU, M. Assessing the impact of environmental impact statements on citizens, 1996, 16 (3), p. 171-182

Unión Europea. Informe de la Comisión al Parlamento Europeo y al Consejo, de 23 de junio de 2003, sobre la aplicación y eficacia de la Directiva de EIA (Directiva 85/337/CEE en su versión modificada por la Directiva 97/11/CE) - Qué avances han realizado los Estados miembros en la aplicación de la Directiva de EIA [COM (2003) 334 final. Disponible en; http://eur-lex.europa.eu/legalcontent/ES/TXT/PDF/?uri=CELEX:52003DC0334\&from=ES

Unión Europea. Directiva 2011/92/UE del Parlamento europeo y del Consejo de 13 de diciembre de 2011 relativa a la evaluación de las repercusiones de determinados proyectos públicos y privados sobre el medio ambiente (texto codificado). Diario Oficial de la Unión Europea L 26/2, 29 de enero de 2012.

UNCED. Conferencia de las Naciones Unidas sobre el Medio Ambiente y el Desarrollo. Declaración de Río sobre el medio ambiente y el desarrollo, adoptada en Río de Janeiro el 14 de junio de 1992 (ONU Doc. A/CONF.151/5/Rev.1). Disponible en: http://www.un.org/spanish/esa/sustdev/agenda21/riodeclaration.htm

VAN DE GRONDEN, ED., BEENTJES, J. and VON DER WONDE, F. Use and effectiveness of EIA in decision-making. Zoetermeer: Netherlands Ministry of Housing, Spatial Planning and the Environment; 1994.

WANG, Y., MORGAN, RK. and CASHMORE, M. Environmental impact assessment of projects in People's Republic of China: new law, old problems. Environmental Impact Assessment Review, 2003, 23, p. 543-79.

WOOD, CM. Environmental impact assessment: a comparative review. 2nd ed. Harlow, Prentice Hall 2003. 
ZAVESTOSKI, S. and SHULMAN S. Democracy and the environment on the internet: electronic citizen participation in regulatory rulemaking. Science, Technology and Human Values, , 2006, vol. 31, no 4, p. 383408. 


\section{Anexo}

\begin{tabular}{|c|c|c|}
\hline & "público" & "público interesado" \\
\hline Convención de Espoo & $\begin{array}{l}\text { una o más personas físicas o } \\
\text { jurídicas }\end{array}$ & - \\
\hline Directiva 2011/92/EU & $\begin{array}{l}\text { "una o varias personas físicas o } \\
\text { jurídicas y, de conformidad con } \\
\text { el derecho o la práctica nacional, } \\
\text { sus asociaciones, organizaciones } \\
\text { o grupos" (Art 1.2. d) }\end{array}$ & $\begin{array}{l}\text { "el público afectado, o que pueda verse afectado, por } \\
\text { procedimientos de toma de decisiones medioambientales } \\
\text { contemplados en el apartado } 2 \text { del artículo } 2 \text {, o que tenga } \\
\text { un interés en el mismo; a efectos de la presente definición, } \\
\text { se considerará que tienen un interés las organizaciones no } \\
\text { gubernamentales que trabajen en favor de la protección del } \\
\text { medio ambiente y que cumplan los requisitos pertinentes } \\
\text { previstos por la legislación nacional. (Art 1.2. e) }\end{array}$ \\
\hline $\begin{array}{c}\text { Real Decreto Legislativo } \\
1 / 2008^{22}\end{array}$ & $\begin{array}{l}\text { "cualquier persona física o } \\
\text { jurídica, así como sus } \\
\text { asociaciones, organizaciones y } \\
\text { grupos constituidos con arreglo } \\
\text { a la normativa que les sea de } \\
\text { aplicación" (Art 2.5) Real Decreto } \\
\text { Legislativo 1/2008 }\end{array}$ & $\begin{array}{l}\text { “a) Todos aquellos en quienes concurran cualquiera de las } \\
\text { circunstancias previstas en el artículo } 31 \text { de la Ley } 30 / 1992 \text {, de } \\
26 \text { de noviembre, de Régimen Jurídico de las Administraciones } \\
\text { Públicas y del Procedimiento Administrativo Común. } \\
\text { b) Cualesquiera personas jurídicas sin ánimo de lucro que } \\
\text { cumplan los siguientes requisitos: } \\
\text { 1.o Que tenga entre los fines acreditados en sus estatutos la } \\
\text { protección del medio ambiente en general o la de alguno de sus } \\
\text { elementos en particular, y que tales fines puedan resultar } \\
\text { afectados por el procedimiento de evaluación de impacto } \\
\text { ambiental. } \\
\text { 2.. Que lleve dos años legalmente constituida y venga } \\
\text { ejerciendo de modo activo las actividades necesarias para } \\
\text { alcanzar los fines previstos en sus estatutos. } \\
\text { 3.o Que según sus estatutos desarrolle su actividad en un } \\
\text { ámbito territorial que resulte afectado por el proyecto que deba } \\
\text { someterse a evaluación de impacto ambiental” (Art 2.6) }\end{array}$ \\
\hline $\begin{array}{l}\text { Decreto-Lei 197/2005 que } \\
\text { modifica o Decreto-Lei } \\
69 / 2000 \text { de } 3 \text { de Maio }\end{array}$ & $\begin{array}{l}\text { "uma ou mais pessoas } \\
\text { singulares, pessoas colectivas de } \\
\text { direito público ou privado, bem } \\
\text { como as suas associações, } \\
\text { organizações representativas ou } \\
\text { agrupamentos" (Art } 2 \text { q) }\end{array}$ & $\begin{array}{l}\text { "os titulares de directos subjectivos ou de interesses legalmente } \\
\text { protegidos, no âmbito das decisões tomadas no procedimento } \\
\text { administrativo de AIA, bem como o público afectado ou } \\
\text { susceptível de ser afectado por essa decisão, designadamente as } \\
\text { organizações não governamentais de ambiente (ONGA)" (Art } 2 \\
\text { r) }\end{array}$ \\
\hline
\end{tabular}

Tabla 1. Conceptos normativos de "público" y " público interesado"

${ }^{22}$ La Ley 21/2013, de 9 de diciembre, de evaluación ambiental (España) ha incorporado la misma definición en el Art. $51 \mathrm{f}$ ).

${ }^{23}$ Decreto-Lei n.o 151-B/2013 de 31 de outubro, de Avaliação de Impacte Ambiental ha incorporado misma definición. 
PROCEDIMIENTO EIA NACIONAL EN ESPAÑA Y PORTUGAL

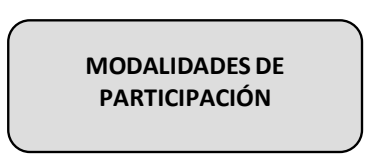

TIPOS DE PARTICIPACIÓN

\section{SUJETOS INTERVINIENTES}
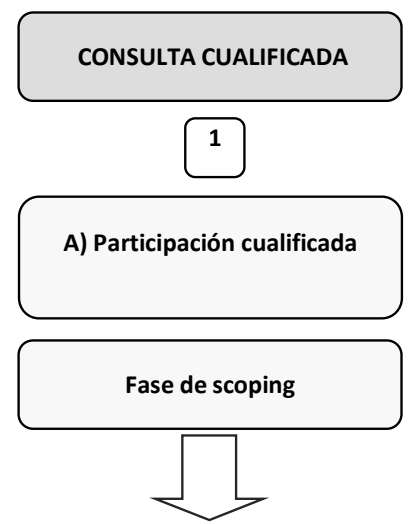

Personas físicas y jurídicas vinculadas al medio ambiente $y$

autoridades afectadas

"Actores cualificados"

- Derecho de consulta-
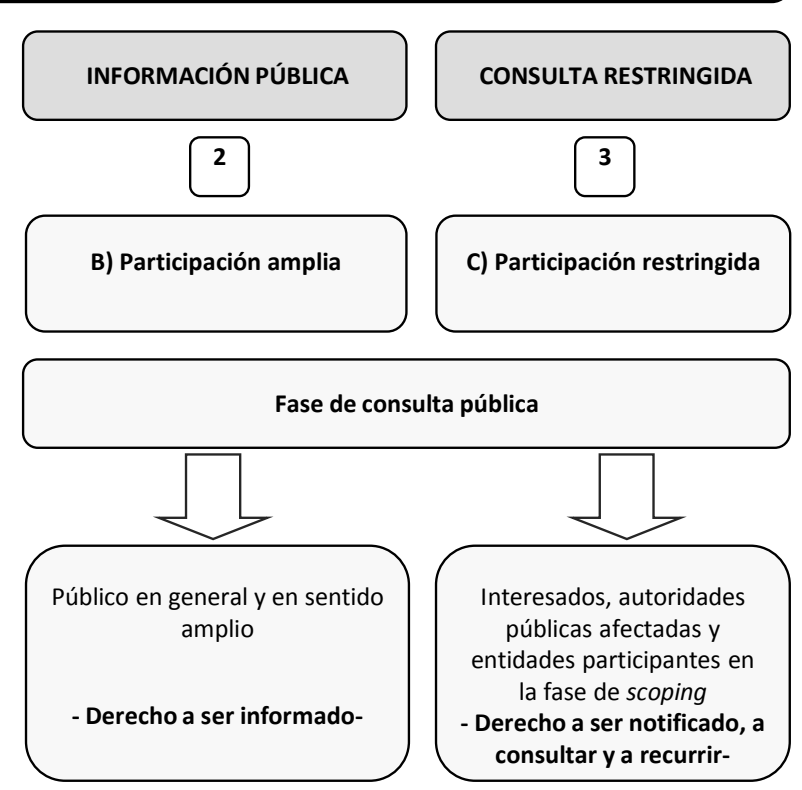

ública

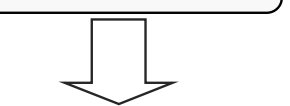

Interesados, autoridades públicas afectadas y entidades participantes en la fase de scoping - Derecho a ser notificado, a consultar $y$ a recurrir-

PROCEDIMIENTO EIA TRANSFRONTERIZO ESPAÑA-PORTUGAL

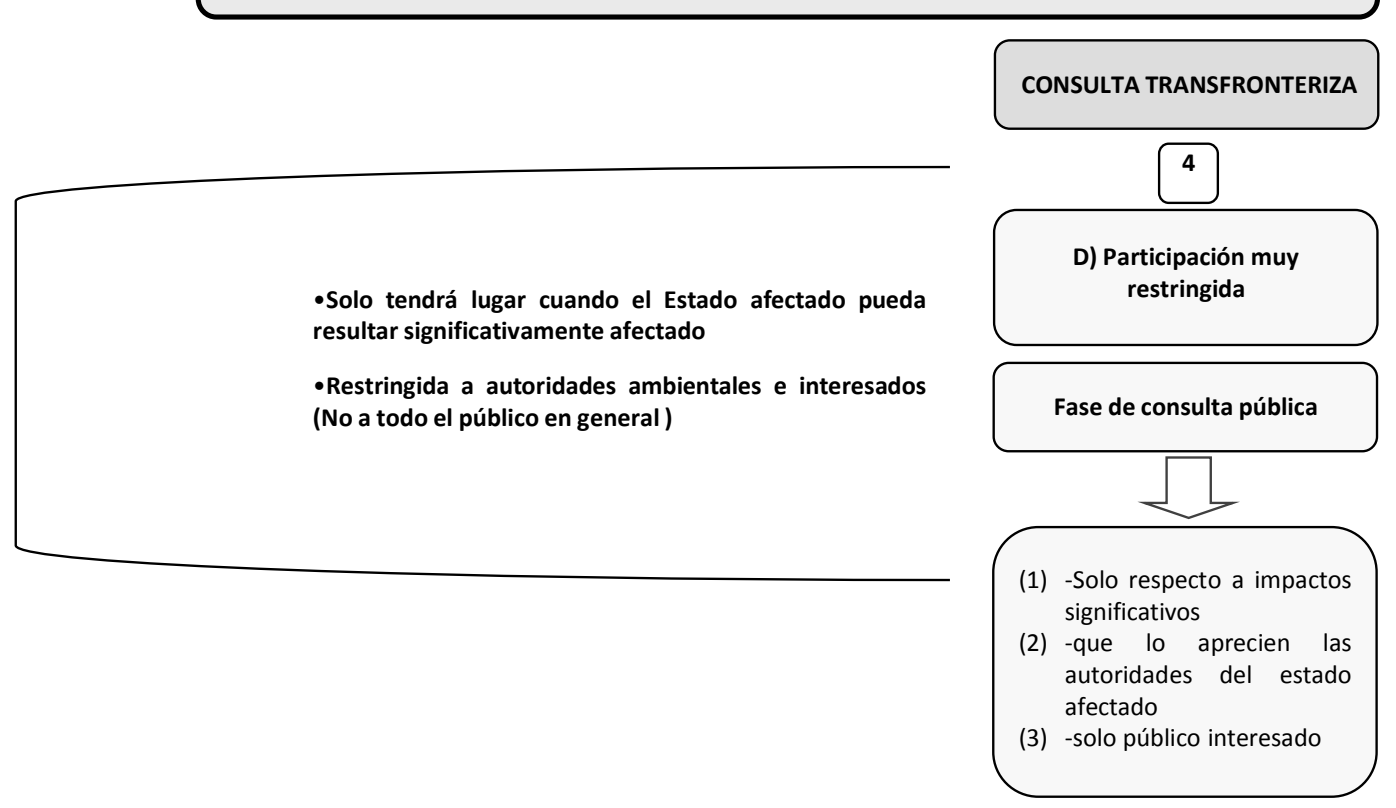

Figura 1. Diagrama de flujo comparativo de las modalidades de participación y actores intervinientes en España y Portugal. 


\begin{tabular}{|c|c|c|c|c|c|}
\hline Tipología & Denominación del proyecto & Lugar & Año & $\begin{array}{l}\text { Estado de } \\
\text { origen }\end{array}$ & $\begin{array}{l}\text { Estado } \\
\text { afectado }\end{array}$ \\
\hline $\begin{array}{l}\text { Infraestructura } \\
\text { ferroviaria }\end{array}$ & $\begin{array}{l}\text { Línea de alta velocidad Madrid-Lisboa, tramo Badajoz-frontera } \\
\text { portuguesa. }\end{array}$ & Badajoz & 2010 & España & Portugal \\
\hline $\begin{array}{l}\text { Infraestructura } \\
\text { ferroviaria }\end{array}$ & $\begin{array}{l}\text { Eje Atlántico de Alta Velocidad, tramo Porriño (Pontevedra)- } \\
\text { frontera portuguesa. }\end{array}$ & Pontevedra & 2010 & España & Portugal \\
\hline Refinería & $\begin{array}{l}\text { Construcción de una refinería de petróleo en Extremadura, en } \\
\text { los municipios de Fuente del Maestre, Los Santos de Maimona y } \\
\text { Villafranca de los Barros (Balboa, Badajoz). }\end{array}$ & Badajoz & 2008 & España & Portugal \\
\hline Extracción de áridos & $\begin{array}{l}\text { Extracción de arena para la regeneración de las playas de A } \\
\text { Braña y A Carteleira en el municipio de Vilanova de Arousa } \\
\text { (Pontevedra). }\end{array}$ & $\begin{array}{l}\text { Pontevedra } \\
\text { / Río Miño }\end{array}$ & 2007 & España & Portugal \\
\hline $\begin{array}{l}\text { Infraestructura } \\
\text { eólica }\end{array}$ & $\begin{array}{l}\text { Parque eólico en la frontera hispano-portuguesa, en el } \\
\text { municipio de Valverde del Fresno (Cáceres). }\end{array}$ & Cáceres & 2008 & España & Portugal \\
\hline $\begin{array}{l}\text { Infraestructura } \\
\text { eléctrica }\end{array}$ & $\begin{array}{l}\text { Línea eléctrica de } 400 \mathrm{kV} \text { en Puebla de Guzmán (Huelva)- } \\
\text { frontera portuguesa. }\end{array}$ & Huelva & 2009 & España & Portugal \\
\hline $\begin{array}{l}\text { Infraestructura } \\
\text { hidraúlica }\end{array}$ & $\begin{array}{l}\text { Aprovechamiento hidroeléctrico del Duero internacional en } \\
\text { Bemposta-Refuerzo de potencia. }\end{array}$ & Bemposta & 2007 & Portugal & España \\
\hline $\begin{array}{l}\text { Infraestructura } \\
\text { ferroviaria }\end{array}$ & $\begin{array}{l}\text { Conexión Ferroviaria de Alta Velocidad entre Madrid- } \\
\text { Lisboa/Porto, 2a fase. Corredor } 1 \text { - Elvas/Badajoz. Lote LTF- } \\
\text { Elvas/Caia }\end{array}$ & Elvas/Caia & 2009 & Portugal & España \\
\hline $\begin{array}{l}\text { Infraestructura } \\
\text { eléctrica }\end{array}$ & $\begin{array}{l}\text { Subestación eléctrica de Tavira y Líneas de la RNT asociadas, } \\
\text { incluyendo nueva conexión con la Red Eléctrica Española. }\end{array}$ & Tavira & 2009 & Portugal & España \\
\hline $\begin{array}{l}\text { Infraestructura } \\
\text { ferroviaria }\end{array}$ & $\begin{array}{l}\text { Conexión ferroviaria de Alta Velocidad entre Oporto y Vigo. } \\
\text { Lote } 1 b \text { - Braga/Valença. }\end{array}$ & $\begin{array}{l}\text { Braga- } \\
\text { Valença }\end{array}$ & 2009 & Portugal & España \\
\hline $\begin{array}{l}\text { Infraestructura } \\
\text { viaria }\end{array}$ & Proyecto IP5 Vilaformoso/frontera española. & $\begin{array}{l}\text { Concelho } \\
\text { de Almeida }\end{array}$ & 2009 & Portugal & España \\
\hline Vía navegable & $\begin{array}{l}\text { Navegabilidad del río Guadiana entre el puente internacional y } \\
\text { Pomarao. }\end{array}$ & Pomarao & 2010 & Portugal & España \\
\hline Campo de golf & Ancoradouro-Almada de Ouro-Golf \& Country Club. & $\begin{array}{l}\text { Concelho } \\
\text { de Castro } \\
\text { Marim }\end{array}$ & 2010 & Portugal & España \\
\hline Trasvase de agua & Refuerzo de abastacemiento de auga a Bragança. & Bragança & 2012 & Portugal & España \\
\hline Extracción minera & $\begin{array}{l}\text { Explotación de recursos minerales en el Río Manzanas", Pozo } \\
\text { del Píngano (Zamora). }\end{array}$ & Zamora & 2009 & España & Portugal \\
\hline Residuos radiactivos & $\begin{array}{l}\text { Emplazamento del Almacén Temporal Centralizado de } \\
\text { Combustible Nuclear gastado y residuos radioactivos de alta } \\
\text { actividad (ATC). }\end{array}$ & Cáceres & 2010 & España & Portugal \\
\hline Central térmica & $\begin{array}{l}\text { Central térmica de ciclo combinado de } 820 \mathrm{MW} \text { en Ledesma } \\
\text { (Salamanca). }\end{array}$ & Salamanca & 2011 & España & Portugal \\
\hline
\end{tabular}

Tabla 2. Relación de casos de consultas transfronterizas entre España y Portugal. Período 2008-2012 Fuente: MAGRAMA (España); MAOTDR (Portugal) y Review of implementation of the Espoo Convention: http://www.unece.org/env/eia/implementation/review_implementation.htm 


\begin{tabular}{|c|c|c|c|c|c|}
\hline Estado de origen & $\begin{array}{c}\mathrm{N} \text { o } \\
\text { administraciones } \\
\text { consultadas }\end{array}$ & $\begin{array}{l}\text { № alegaciones } \\
\text { recibidas } \\
\text { administraciones } \\
\text { consultades }\end{array}$ & $\begin{array}{c}\text { № alegaciones } \\
\text { de apreciación } \\
\text { efectos } \\
\text { significativos }\end{array}$ & $\begin{array}{c}\text { № } \\
\text { observaciones } \\
\text { de empresas y } \\
\text { particulares }\end{array}$ & $\begin{array}{c}\text { No de } \\
\text { alegaciones } \\
\text { contestadas y/o } \\
\text { tomadas en } \\
\text { consideración } \\
\text { por Estado } \\
\text { origen }\end{array}$ \\
\hline $\begin{array}{c}\text { (1) } \\
\text { Línea AVE } \\
\text { Badajoz-Portugal }\end{array}$ & 23 & 2 & 0 & 0 & - \\
\hline $\begin{array}{c}\text { (2) } \\
\text { Refinería de } \\
\text { Balboa }\end{array}$ & 13 & 9 & 6 & 0 & 1 \\
\hline $\begin{array}{l}\text { (3) } \\
\text { Parques eólicos en } \\
\text { Cáceres }\end{array}$ & 13 & 5 & 1 & 0 & 1 \\
\hline $\begin{array}{c}\text { (4) } \\
\text { Línea eléctrica en } \\
\text { Huelva }\end{array}$ & 7 & 1 & 0 & 0 & 1 \\
\hline $\begin{array}{c}\text { (5) } \\
\text { Mina en Zamora }\end{array}$ & 7 & 6 & 5 & 0 & - \\
\hline $\begin{array}{c}\text { (6) } \\
\text { Línea AVE Porriño } \\
\text { frontera } \\
\text { portuguesa }\end{array}$ & 7 & 1 & 1 & 0 & 1 \\
\hline $\begin{array}{c}\text { (7) } \\
\text { Central térmica en } \\
\text { Salamanca }\end{array}$ & 17 & 0 & 0 & 0 & - \\
\hline
\end{tabular}

Tabla 3.- Análisis de los procesos de participación pública. Consultas transfronterizas en Portugal

(1) Portugal envió el resultado de las consultas el 20/07/2011. En la DIA se refieren que se se recibieron alegaciones de la Autoridade Nacional de Comunicaçoes y de Estradas de Portugal, S.A señalando que la actuación no interfiere con ningún servicio o infraestructura responsabilidad de estas empresas. (Declaración de impacto ambiental del proyecto "Línea de alta velocidad Madrid-Lisboa, tramo Badajoz-frontera portuguesa, Badajoz", Boletín oficial del Estado, martes 16 de agosto de 2011, núm. 196, , p. 92660).

(2) En concreto la autoridades portuguesas y WWF/ADENA solicitaron la ampliación de la zona de estudio en la evaluación del riesgo de mareas negras, para poder descartar un posible impacto sobre las playas del Algarve y la zona propuesta como área marina protegida frente de Doñana, y en su informe se cuestionó la viabilidad del vertido de la refinería y sus efectos sobre el Guadiana, y el riesgo de vertido de crudo o producto en la monoboya de Huelva, que podría afectar a las costas de Portugal. Asimismo, en diciembre de 2011 tuvo lugar una reunión con las Autoridades Portuguesas, en la que el promotor expuso las conclusiones de los estudios efectuados sobre los posibles impactos transfronterizos. Finalmente la DIA de 16/07/2012 resultó ser 
desfavorable por los previsibles efectos significativos sobre el medio ambiente. (Declaración de impacto ambiental del proyecto "Construcción de una refinería de petróleo en Extremadura, término municipal de Los Santos de Maimona -Badajoz-, y sus infraestructuras asociadas -Sevilla y Huelva-", Boletín oficial del Estado, 30 de julio de 2012, núm. 181, p. 54698).

(3) En la DIA consta que la DGEyCA de la Comunidad Autónoma de Extremadura valora muy positivamente la participación de Portugal en el proceso de evaluación ambiental del proyecto, teniendo en alta consideración las puntualizaciones y opiniones resultado de las consultas efectuadas, que fueron tenidas en cuenta a la hora de elaborar la DIA. Como medidas compensatorias se indican la reubicación de un muladar existente en la Sierra de Malcata en territorio portugués y distribución de una red de plataformas y muladares alternativos en una zona a convenir con la APA. (Declaración de impacto ambiental del proyecto "Parque eólico La Malvana, en el término municipal deValverde del Fresno", Diario Oficial de Extremadura, 16 de diciembre de 2010, núm. 240, p. 29796).

(4) El envío de alegaciones consistió en una remisión de la DIA recaída en Portugal respecto al proyecto eléctrico de conexión con el proyecto español. Esta DIA se advierte de posibles impactos ambientales relativos a las aves y zonas de montado de Portugal y se refiere que los proyectos fueron objeto de un análisis conjunto (España-Portugal) de acuerdo con un documento de la Red Eléctrica de España de noviembre de 2007. (Declaración de impacto ambiental del proyecto "Línea eléctrica a 400 kV, Puebla de Guzmán - frontera portuguesa, términos municipales varios, Huelva", Boletín oficial del Estado, 3 de noviembre de 2011, núm. 265, p. 115000-115001).

(5) La consulta en Portugal reveló una fuerte oposición por su gran impacto ambiental siendo objeto de una pregunta parlamentaria al Gobierno portugués: No consta la emisión de la DIA. http://www.pcp.pt/impactosdecorrentes-da-explora\%C3\%A7\%C3\%A3o-de-recursos-mineiros-quartzo-em-solo-espanhol-projecto-

\section{\%C2\%ABrio-manza}

(6) El Relatório de consulta en Portugal solo informa de una alegación presentada por el ICNB del Ministério do Ambiente e do Ordenamento del Território que manifiesta una preferencia por la Alternativa 1 por ser la de menor impacto. Sin embargo España finalmente optó por la alternativa 2 justificando ser la más adecuada desde el punto de vista ambiental. (Declaración de impacto ambiental del proyecto "Eje Atlántico de Alta Velocidad, tramo frontera portuguesa-Porriño, Pontevedra", Boletín oficial del Estado, 10 de octubre de 2011, núm. 244, p. 106423).

(7) Según se refiere en el Relatório de Consulta Pública enviado por Portugal de las 8 administraciones afectadas no se recibieron alegacions y de las 9 entidades externas consultadas solo se recibió una alegación del Instituto da Água (INAG). El informe portugués refiere que no fueron observados impactos significativos en el territorio portugués si bien fueron identificadas lagunas en la información suministrada sobre el proyecto y sobre la afectación de los potenciales impactos negativos sobre del territorio portugués. 


\begin{tabular}{|c|c|c|c|c|c|}
\hline $\begin{array}{c}\text { Estado de } \\
\text { origen }\end{array}$ & $\begin{array}{c}\text { № } \\
\text { administraciones } \\
\text { consultadas }\end{array}$ & $\begin{array}{c}\text { № alegaciones } \\
\text { recibidas } \\
\text { administraciones } \\
\text { consultades }\end{array}$ & $\begin{array}{c}\text { № alegaciones } \\
\text { de apreciación } \\
\text { efectos } \\
\text { significativos }\end{array}$ & $\begin{array}{c}\text { № } \\
\text { observaciones } \\
\text { de empresas y } \\
\text { particulares }\end{array}$ & $\begin{array}{c}\text { № de alegaciones } \\
\text { contestadas y/o } \\
\text { tomadas en } \\
\text { consideración por } \\
\text { Estado origen }\end{array}$ \\
\hline $\begin{array}{l}\text { (1) } \\
\text { Aprovechamiento } \\
\text { hidroeléctrico } \\
\text { Bemposta }\end{array}$ & 0 & 0 & 0 & 0 & 0 \\
\hline $\begin{array}{c}\text { (2) } \\
\text { AVE Elvas / } \\
\text { Badajoz- Sección } \\
\text { Elvas / Caia }\end{array}$ & 8 & 4 & 3 & 0 & 0 \\
\hline $\begin{array}{c}\text { (3) } \\
\text { Estación eléctrica } \\
\text { de Tavira }\end{array}$ & 24 & 1 & 1 & 0 & 1 \\
\hline $\begin{array}{c}(4) \\
\text { AVE Oporto-Vigo }\end{array}$ & 12 & 1 & 1 & 0 & 1 \\
\hline $\begin{array}{c}\text { (5) } \\
\text { Navegabiidad río } \\
\text { Guadiana }\end{array}$ & 12 & 8 & 8 & 0 & - \\
\hline $\begin{array}{c}\text { (6) } \\
\text { Ancoradouro }\end{array}$ & 7 & 4 & 3 & 0 & - \\
\hline
\end{tabular}

Tabla 4.- Análisis de los procesos de participación pública. Consultas transfronterizas en España

(1) Las autoridades españolas no enviaron resultados de consultas a Portugal sin embargo en aplicación del Protolo de Colaboración (2008) entre ambos países se mantuvo una reunión con las autoridades portuguesas al objeto de integrar condicionamientos extemporáneos de España. Esto motivaría la modificación de la DIA originaria y se emitiría una tercera, el 22 de enero de 2009: "Considerando os pareceres ( das autoridades espanholas) e a sequente proposta de alteração de DIA da Autoridade de Avaliação de Impacte Ambiental (AIA), emito uma alteração à DIA emitida a 15 de Fevereiro de 2008 alterada a 6 de Maio de 2008..."(Declaração de Impacte Ambiental do projecto "Aproveitamento Hidroeléctrico do Douro Internacional Bemposta - Reforço de Potência", 22 de Janeiro de 2009, p. 1. Disponible en: http://siaia.apambiente.pt/AIADOC/AIA1731/DIA1731.pdf).

(2) Los resultados de las consultas españoles fueron enviadas a Portugal el 06/10/2008 con posterioridad a la DIA recaída el 27/05/2008: "... foram desenvolvidos os contactos estabelecidos com as Autoridades Espanholas. No entanto, até à data, não foi remetido o parecer daquelas autoridades". (Declaração de Impacte Ambiental do projecto "Ligação Ferroviária de Alta Velocidade entre Madrid - Lisboa/Porto, 2a fase. Corredor 
1 - Elvas/Badajoz. Lote LTF - Elvas/Caia", 27 de mayo de 2008, p. 16 . Disponible en: http://siaia.apambiente.pt/AIADOC/AIA1833/DIA1833.pdf).

(3) Las autoridades españolas dentro del plazo establecido destacaron en sus alegaciones que el cruce de la línea eléctrica con la frontera se producía sobre el LIC "Río Guadiana y Ribera del Chanza", el cual generaba un impacto visual, en una zona en la que el paisaje constituía uno de los valores más destacados. Por ello se solicitaba a Portugal que en la medida que resultase técnicamente posible, se estudiasen alternativas constructivas que lo evitasen, como el soterramiento de la línea en ese tramo. La administración ambiental portuguesa, como resultado de un analisis conjunto con España, adoptaría la alternativa de menor afectación de los valores ambientales en la declaración ambiental que adoptaría. (Declaração de Impacte Ambiental do projecto "Subestação de Tavira e Linhas da RNT associadas, incluindo nova ligação com a Rede Eléctrica Espanhola Subestação", de 4 de febrero de 2009, p. 3. Disponible en: http://siaia.apambiente.pt/AIADOC/AIA1749/DIA1749.pdf)

(4) Portugal recogió en el apartado 10 del Parecer da Comissão de Avaliação que los comentarios de España eran solo un conjunto de condiciones y recomendaciones a tener en cuenta. La DIA declara que se consideraron esas condiciones pero pero no especifica claramente cómo las alegaciones españolas fueron tenidos en cuenta. (Declaração de Impacte Ambiental do projecto "Informe de Ligação Ferroviária de Alta Velocidade entre Porto e Vigo, Lote 1B - Troço Braga/Valença", 29 de Dezembro de 2010, p.23. Disponible en: http://siaia.apambiente.pt/AIADOC/AIA2102/DIA2102.pdf.

(5) En la DIA recaída se hace mención a la consideración de las alegaciones requeridas por las autoridades españolas: "O Estado Espanhol identifica ainda um conjunto de estudos que considera necessários à avaliação do Projecto, parte dos quais foram já desenvolvidos no EIA, e parte os quais são solicitados na presente Declaracão para a fase de Projecto de Execução." (Declaração de Impacte Ambiental do projecto "Navegabilidade do río Guadiana entre a Foz e o Pomarão", 22 de septiembre de 2011, p, 13. Disponible en: http://siaia.apambiente.pt/AIADOC/AIA2171/DIA2171.pdf)

(6) España envió el resultado de la participación pública a Portugal mediante un primer informe el 24/03/2011 y un segundo informe con una alegación extemporánea el 20/09/2011. 